\title{
APPROACH OF DEVELOPING SPATIAL DISTRIBUTION MAPS OF SOIL NUTRIENTS
}

\author{
Yong Yang ${ }^{1, *}$, Shuai Zhang ${ }^{1}$ \\ ${ }^{1}$ College of Information and Electrical Engineering, Shenyang Agricultural University, \\ Shenyang, China, 110161 \\ * Corresponding author, Address: P.O. Box 43, College of Information and Electrical \\ Engineering, Shenyang Agricultural University, 120 Dongling Road, Shenyang, 110161, P. R. \\ China, Tel: +86-24-88036221, Fax: +86-24-88487863, Email: yangsyau@163.com
}

Abstract: One of the major components of precision agriculture is the precision fertilization. The basic principle of precision fertilization is to adjust the fertilizer input according to the specific circumstances or properties of soils in each location for the least waste and the highest profit. The paper presents a feasible approach for developing the spatial distribution map of soil nutrients based on a kind of GIS software, the ArcView. According to the field sampling data and localities measured by GPS a database of soil nutrients was set up. Using the semi variance function and the Kriging interpolations algorithm upon geostatistics theory the field data were analyzed, and then the graphic editor of the ArcView was applied to produce soil nutrient spatial distribution map, which describes the precision of the algorithm and distribution range of soil nutrients. This research is a methodological contribution to precision agriculture and lays the ground for precise application of fertilizers.

Keywords: Soil nutrients; Spatial distribution map; ArcView; Geostatistics

\section{INTRODUCTION}

The ideas for sustainable development of agriculture and precision agriculture theory have been pushed forward. The precision agriculture requires a new theory and technology in terms of reasonable fertilization. The speedy development of the world agriculture was gained under the 
condition of a large amount of input of chemicals or mineral sources of energy, such as chemical fertilizer and pesticide (Liu Jintong, et al., 2002). But, ecological and environmental problems, for example, increased soil erosion, pollution of agricultural products and groundwater and enrichment of nutrition in water bodies, etc., have caused the extensive concern of international community.

The traditional even fertilizing method is not scientifically suitable and efficient to apply fertilizer in places with different soil nutrients, because soil fertility at different regions differs from place to place significantly. And overuse fertilizers can certainly lead to a waste of fertilizer resources and a serious environmental pollution. The Geostatistics has been proved to be one of the most effective ways to analyze the characteristics of soil nutrient spatial distribution and the pattern of variation. The Kriging interpolation algorithm is the most useful and optimal one in geostatistics that uses of initial data in a region as well as the structural characteristics of variable function to estimate the unknown values by the linear unbiased estimation.

The basic technological principle of precision fertilization is to adjust the fertilizer input according to the specific circumstances or properties of soils in each location for the least waste and the highest profit by fully understanding the variation of soil nutrients. Therefore, understanding the spatial variability of soil nutrient is the first step and the pre-condition for precision fertilization. The spatial distribution map of soil nutrient, developed by using the geostatistics as a principle and the software GIS as a tool, can reflect the spatial variability of nutrient and also make the balanced fertilization possible.

\section{COMPUTER ENVIRONMENT}

The computer tool of developing spatial distribution maps of soil nutrients is the ArcView GIS. The ArcView GIS is a geography information system software that was developed by the American Environment System Research Institute (ESRI). As a GIS software, the ArcView GIS's key function is the desk mapping and spatial analysis, etc. Owing to its building on the objectoriented data structure, data management and the analysis merit of ArcView can be fairly nimble, and ArcView can read the data taken from the Coverage and Grid of ARC/INFO, also the data from AutoCAD and data outside the base, etc. As far as his flexibility, user can control every element in ArcView's environment because of Avenue's programming language, through using Avenue's script, man can visit the object and class of ArcView's inside, and through its approaches of the internal geostatistical algorithms, one can carry on the geostatistics operations. 


\section{ALGORITHM}

It is a science about studying natural phenomena of the randomness and structure in spatial distribution with the variable theory in region serving as foundation and the variation function as the basic tool. The Geostatistics has been proved to be one of the most effective ways to analyze the characteristic of the soil nutrient spatial distribution and the law of variation (Sun Hongquan, 1990).

\subsection{Regional variable theory}

The regional variable theory is one kind of real function that possesses numerical values in the space, its every point in the space means a definite numerical value, and when the point moves to the next point, the function value changes (White J. G. et al., 1997). The main characteristic of the region variable is the spatial correlation that it assumes the fixed level in the fixed scope, and after transcending this scope, the correlation becomes so weak that it disappears in the end, this quality is very difficult for the general statistics methods to recognize, but very useful for geostatistics.

\subsection{The semi variance function}

Semi variance function is a group of functions to describe the spatial variation in soil, which can show the change between the observation values of different distances (Campbell J. B. et al., 1978). The so-called semi variance is the semi variance of the observation value between any two points, the same as:

$$
\mathrm{r}(\mathrm{h})=\operatorname{Var}[\mathrm{Z}(\mathrm{X}+\mathrm{h})-\mathrm{Z}(\mathrm{X})] / 2
$$

in the equation, $\mathrm{Z}(\mathrm{X}+\mathrm{h})$ and $\mathrm{Z}(\mathrm{X})$ are for the measured value of soil nutrient, $r(h)$ is for semi variance of an interval of $h$, it is enlarged along with the increase of $h$ in the fixed scope, and this value is stable when the interval is more than the biggest correlation distance.

\subsection{The Kriging interpolations}

The data between samples need to be estimated. Because the soil is sampled intermittently, and this estimation course is called the interpolation, that is a method used to estimate the unknown soil data in the neighborhood with the data of sample (Gaston L. A., 2001). The Kriging interpolation is the most useful and optimal one in use of the initial data in region and the structure characteristic of variable function to estimate the unknown value 
by the linear unbiased estimation, the nature is actually a weighted average of partial estimation as below:

$$
Z\left(X_{0}\right)=\sum_{i=1}^{n} \lambda_{i} Z\left(X_{i}\right)
$$

in the equation, $\mathrm{X}_{0}$ is a point waiting for estimation, $\mathrm{Z}\left(\mathrm{X}_{0}\right)$ is the interpolated estimation value on the point of $\mathrm{X}_{0} . \mathrm{Z}\left(\mathrm{X}_{\mathrm{i}}\right)$ are real measured values of a certain number of observation points near $X_{0}, \lambda_{i}$ are weights which describe spatial variation in consideration of spatial variation weights in semi variance map. Therefore, the estimation of $\mathrm{Z}$ value is unbiased.

Because of

$$
\sum_{i=1}^{n} \lambda_{i}=1
$$

the estimated bias is minimum, which can be worked out by the following equation.

$$
\delta^{2}=B^{T}\left\lfloor\begin{array}{l}
\lambda \\
\mu
\end{array}\right\rfloor
$$

where B is semi variance matrix between estimated point and other points, $\mu$ is Lagrange's parameter.

\section{MAPPING}

\subsection{Data acquisition}

The samples were taken in $34 \mathrm{hm}^{2}$ of dry farmland. For the difference of size and fertility, a sample $(0-20 \mathrm{~cm})$ was collected from every $0.49 \mathrm{hm}^{2}$ in the net $(70 \mathrm{~m}$ to the south and $70 \mathrm{~m}$ to the north) and 84 samples were obtained in total. The latitude and longitude of sampling sites were recorded by the global position system (GPS), and at the same time, we made a careful investigation about the outcome and manure application circumstances in the place for the recent years. After gaining the sample of soil, we started to analyze them in laboratory to gain each nutrient value of every soil sample.

\subsection{The data analysis and mapping}

An information database of soil nutrient and fertilizer information was set up by using small-size database tool Microsoft Access. The measured soil nutrient content and coordinate in samples, and all the concerned information of fertilization and yield over the past years were input into the 
database. Through the extension module Database Access of ArcView and by using ODBC the ArcView is linked to the information database of soil nutrient and fertilizer information. Selecting a table which contains the coordinate and soil nutrient content of samples and using the event subject commands the table will be generated in map form, namely the distribution map of soil sample. Then, it is the time to realize the interpolation algorithm in Avenue's language, and with the ArcView's graphic editor and by way of classifying the soil nutrient values again to define the precision of soil nutrient values and the colors of each region section to produce the spatial distribution map of soil nutrients. Different color represents different range of nutrient value. The corresponding area of color is to be used to examine each nutrient value scope and possibly to know the condition -rich or poorof the soil nutrient in the map.

\subsection{Mapping example}

We can reclassify soil nutrients and determine precision of the nutrients and colors of various fields by using graphic editor provided by ArcView, and as the result we can generate the following map.

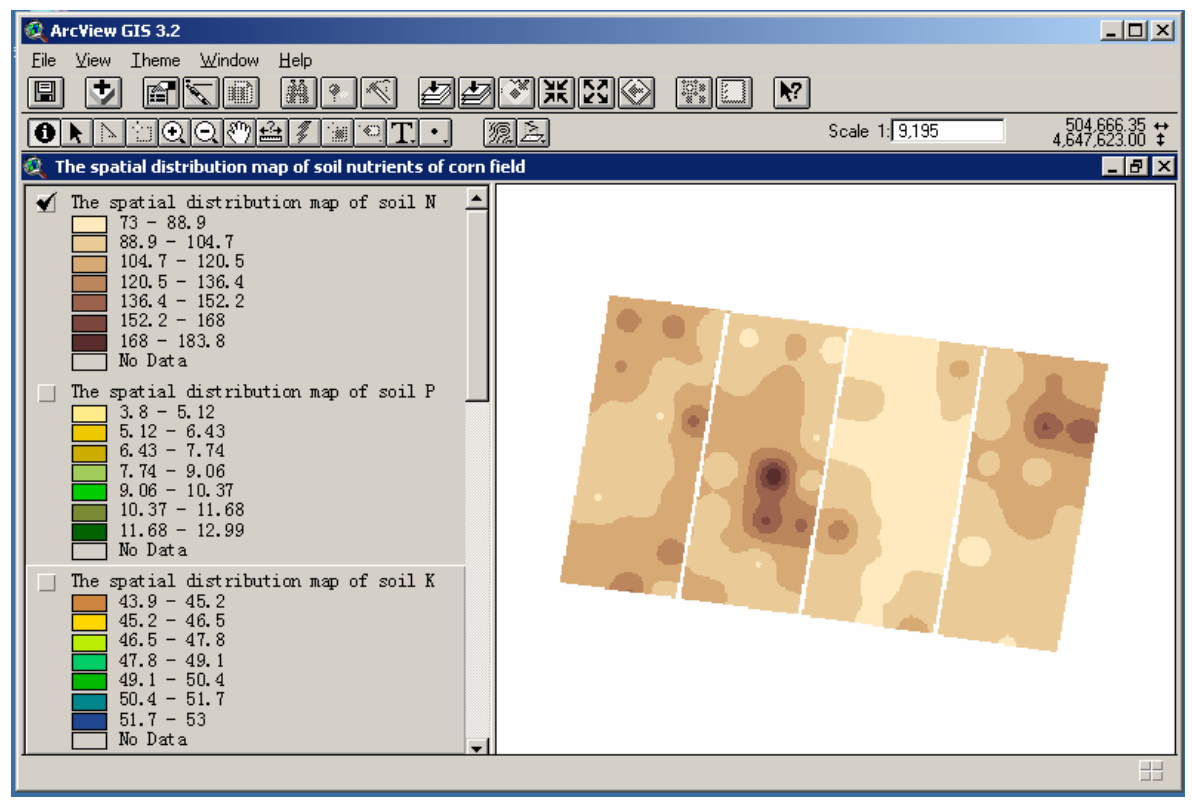

Figure 1. The spatial distribution map of soil nutrients of corn field

The above figure can be divided into two parts, the right part is map area and the left is the legend area. When a legend is selected, a corresponding map will appear in the right part. The different colors in the left part refer to 
the different ranges of nutrients values, from which one can know the status of a nutrient, while the nutrient level at a certain point can be known by using the "identity tools" of the ArcView.

\section{CONCLUSIONS}

The core of precision agriculture is to obtain different information in space and time about the crop outcome of farmland and environmental factors in a small area (of soil structure, soil fertility, topography, climate and disease, etc.), to analyze different causes, thus to take some feasible technological measures. It has some disadvantages for wasting fertilizers due to over input and even use of fertilizers. The geostatistics method can be used for quantitative analysis in the research on soil nutrient spatial variation. The semi variance map is the foundation of explaining the spatial variation structure of soil nutrients, while the Kriging's interpolation algorithm among them can predict the soil nutrient values in the unsampled areas with the model of the semi variance utilization map.

By means of generating the soil nutrient spatial distribution map on the geography information system platform, ArcView, the numerical map of soil quality has been realized. It is more accurate than the traditional soil mapping model because of the consideration of spatial variability of soil nutrients. Utilization of the new technique can improve the quality of fertilizing, reduce environmental pollution resulted from over fertilization, and increase agricultural production efficiency. The research is significant to modern agriculture, and especially to precision agriculture.

\section{ACKNOWLEDGEMENTS}

This study has been funded by the natural science foundation of Liaoning province of P. R. China (Project Number: 20052126). Sincerely thanks go to the Tieling Municipal Department of Agriculture for providing the experimental base and data investigation for this study.

\section{REFERENCES}

Alem M. H., Azari A. B. and Nielsen D. R. 1988. Kriging and univariate modeling of a spatial correlated date. Soil technology. 1(2):133-147.

Baker W. H. and Carroll S. D. 1996. Assessment of rice yield and fertility using site-specific technologies. Better Crops with Plant Food, 80(3):24-29. 
Beetz H. F. 1994. Site-specific nutrient management systems for the 1990s. Better Crop, Vol. 78, No. 4:14-19.

Brannon G. R., Hajek B. F. 2001. Update and recorrelation of soil survey using GIS and statistical analysis. Soil Science Society of America Journal. 64(2):679-680.

Burrough P. A. 1991. Sampling designs for quantifying map unit composition. Spatial variability of soils and landforms, International Soil Science Society Working Group of Soil \& Moisture Variability in Time \& Space/American Society of Agronomy, the Crop Science Society of America \& the Soil Science Society of America, 89-126.

Cahn M. D., Hummel J. W. and Brouer B. H., 1994. Spatial analysis of soil fertility for sitespecific crop management. Soil Science Society of America Journal. 58:1240-1458.

Campbell J. B. 1978. Spatial variation of sand content and $\mathrm{pH}$ within single contiguous delineation of two soil mapping units. Soil Sci. Am. J. (42):460-464.

Gaston L. A. 2001. Spatial Variability of soil properties and weed population in the Mississippi delta. Soil Science Society of American Journal. (65):470-479.

James D. W. and Hurst R. L. 1995. Soil sampling technique for band-fertilized, no-till fields with Monte Carlo Simulations. Soil Science Society of America Journal, 59:1768-1772.

Liu Jintong, etc. 2002. Refined Precision Agriculture Outline. Beijing. China Meteorological Publishing House (in Chinese).

McBraney A. B. and Webster R. 1986. Choosing functions for semi-variograms of soil properties and fitting them to sampling estimates. Journal of Soil science, 37:617-639.

Mulla D. J. 1991. Using geostatistics and GIS to manage spatial patterns in soil fertility, In Automated agriculture for the 21st century. Proc. Symposium. Chicago, IL. 16-17. Dec. 1991. ASAE, St Joseph, MI. 336-345.

Proc-Hermandez R. 1993. Spatial interpolation in geographical information systems. Proceeding of GIS'93, the Canadian conference on GIS. Energiy mines and resources of Canada.

Rogowski A. S. 1995. Quantifying soil variability for GIS application. I. estimates of position. International Journal of gergraphical Information Systems, 9:81-94.

Schnug E., Murphy D. P. L., Haneklaus S. and Evans E. J. 1993. local resource management in computer aided farming: A new approach for sustainable agriculture. Optimization of Plant Nutrition, M. A. C. Fragoso and M. L. van beusichem (Eds), Netherlands, Kluwer Academic Publisher, 657-663.

Sun Hongquan. 1990. Geology Statistics and Application. Beijing. China Mining Industry University Publishing House (in Chinese).

Tom McGraw, 1994. Soil level Variability in Southern Minnesota. Better Crop, (7894):24-25.

Van Groienigen J. W. 2000. Soil sampling strategies for precision Agriculture research under sahelian condition. Soil Science society of America Journal. 64:1674-1680.

Webster R. and McBraney A. B. 1987. Mapping soil fertility at Broom's Barn by simple kriging. J. Sci. Food Agric. 38:97-115.

White J. G., Welch R. M. and Norvell W. A. 1997. Soil Zn map of the USA using geostatistical and geographic information system. Soil Sci. Soc. Am. J. (61):185-194.

Yost R. S., Uehara G. and Fox R. L. 1982. Geostatistical analysis of soil chemical properties of large land areas. I. semivariograms. Soil Science Society of American Journal. 46:10281037. 